\title{
Karbondioksit Emisyonu, Ekonomik Büyüme, Enerji Tüketimi İlişkisi: Türkiye İçin Bir ARDL Sınır Testi Yaklaşımı
}

Fındı Ö̈lem ALPER, Department of Economics, Omer Halisdemir University, Turkey; e-mail: ozknozlem@gmail.com

Ali Eren ALPER, Department of Public Finance, Omer Halisdemir University, Turkey; e-mail: alierenalper@gmail.com

\section{Carbon dioxide Emission, Economic Growth, Energy Consumption Relation: ARDL Bound Testing Approach for Turkey}

\begin{abstract}
The aim of this study is to conduct research about the relation of carbon dioxide emission $\left(\mathrm{CO}_{2}\right)$, economic growth (GDP) and crude oil consumption (OIL) in Turkey with the cointegration test. For this reason the ARDL Bound Testing approach developed by Pesaran et.al. has been used for the 1985-2014 period. The test results indicate the existence of a long term relationship among the variables with the elasticity values 0.80 for economic growth and 0.11 for energy consumption. Acquired long term coefficients show a significant relationship among $\mathrm{CO}_{2}$ emission, GDP and OIL. In other words, it has been determined that economic growth and energy consumption increased environmental pollution, however economic growth harmed the environment more than energy consumption.
\end{abstract}

Keywords $\quad: \quad$ Economic Growth, Environmental Pollution, ARDL Bound Testing.

JEL Classification Codes : $\quad$ C32, O44, Q56.

\section{$\ddot{\mathbf{O} z}$}

$\mathrm{Bu}$ çalışmanın amacı Türkiye'de karbondioksit emisyonu $\left(\mathrm{CO}_{2}\right)$, ekonomik büyüme (GDP) ve ham petrol tüketimi (OIL) ilişkisini eşbütünleşme testiyle araştırmaktadır. Bu amaçla Pesaran vd. (2001) tarafından geliştirilmiş olan ARDL Sınır Testi yaklaşımı 1985-2014 dönemi için kullanılmıştır. Test sonuçları ekonomik büyüme için 0.80 ve enerji tüketimi için 0.11 elastikiyet değerleri ile değişkenler arasında uzun dönemli bir ilişkinin varlığını göstermektedir. Elde edilen uzun dönemli katsayılar, $\mathrm{CO}_{2}$ emisyonu ile GDP ve OIL arasında, beklentilerle uyumlu şekilde pozitif ve istatistiki olarak anlamlı bir ilişkiyi göstermektedir. Diğer bir ifadeyle ekonomik büyüme ve enerji tüketiminin uzun dönemde çevre kirliliğini arttırdığı ancak ekonomik büyümenin, enerji tüketimine göre çevreye daha fazla zarar verdiği tespit edilmiştir.

Anahtar Sözcükler $\quad$ : Ekonomik Büyüme, Çevre Kirliliği, ARDL Sınır Testi. 
Alper, F.Ö. \& A.E. Alper (2017), “Karbondioksit Emisyonu, Ekonomik Büyüme, Enerji Tüketimi İlişkisi: Türkiye İçin Bir ARDL Sınır Testi Yaklaşımı”, Sosyoekonomi, Vol. 25(33), 145-156.

\section{Giriş}

Endüstri devrimi sadece ülkeler arasında hızlı ekonomik büyümeyi beraberinde getirmekle kalmadı, günümüzün en büyük problemlerinden biri olan küresel ısınma ve iklim değişikliğini de beraberinde getirdi. Endüstri devriminin önemli etkilerinden biri de insan ve hayvan gücü temelli organik ekonomileri, fosil yakıt temelli inorganik ekonomilere dönüştürmesidir. Fosil yakıtların kullanımı atmosferdeki karbon seviyelerini sürekli ve eşit olmayan bir biçimde arttırmaya başlamıştır. Bunun sonucu olarak da atmosferde tutulan sıcaklık miktarı artmıştır.

2007 yılında toplanan "Hükümetler arası İklim Değişikliği Paneli Raporu (IPCC)" küresel ortalama sıcaklıklarla, sera gazı emisyonu arasında yakın bir ilişki olduğunu ortaya koymuştur. IPCC (2007)' e göre küresel ısınmadaki 1.1 ile 6.4 derecelik bir artış 2100 yılına kadar deniz seviyesinde 16.5 ile $53.8 \mathrm{~cm}$. yükseliş yaratacaktır (IPCC, 2007). Sera gazı salınımına bağlı olarak oluşan küresel ısınmanın sonuçları ülkelerin sosyal ve doğal karakteristiklerine bağlı olarak değişmektedir (Tiwari, 2011: 86). Stern vd. (2006)'ya göre küresel ısıdaki bu radikal değişim bütün ülkeleri etkileyecek ancak ülkeler arasında en erken ve en sert etki, fakir ve kalabalık ülkelerde, ki bu ülkeler en az sera gazı salınımı yapan ülkelerdir, ortaya çıkacaktır.

Gro Harlem Brundtland'ın 1987 tarihli “Ortak Geleceğimiz” başlıklı raporunda sürdürülebilir büyümenin tanımını yapmıştır. Brundtland (1987)'e göre sürdürülebilir büyüme "Bugünün ihtiyaçlarını, gelecek nesillerin kendi ihtiyaçlarını karşılama kabiliyetini riske atmadan karşılamaktır" (Brundtland vd., 1987: 16). Küresel 1sınma ve iklim değişikliğinin yarattığı en büyük tehdit büyüme ve gelişmenin sürdürülebilirliğine imkan vermemesidir. Bu nedenle dünyamızın en ciddi çevre problemidir. Bu şekilde artan çevresel tehdit akademisyenleri ve politika yapıcıları küresel ısınmanın dünya ekonomisine yaptığı katkıları incelemeye itmiştir.

Gelişmiş ülkeler bu sorunla savaşmak için 1990'ların başından itibaren çeşitli önemli çevresel antlaşmalar imzalamışlardır. Bu antlaşmalardan ilki 1992 yılında Rio de Janeiro'da imzalanan "İklim Değiş̧ikliği Üzerine Birleşmiş Milletler Temel Konvansiyonu (UNFCCC)'dur”. UNFCCC ile kararlaştırılan “Kyoto Protokolü” 11 Aralık 1997'de Kyoto'da imzalandı ve 16 Şubat 2005'de 37 gelişmiş ülkeye bağlayıcı sınırlar koyan hükümleriyle devreye girdi. Kyoto Protokolü'ne göre gelişmiş ülkeler atmosfere zarar verici gaz emisyonlarını 2008-2012 arasında, 1990 yılı seviyelerinin en az \%5 altına çekmek zorundadırlar (Özcan, 2013: 1138).

İklim değişikliğine sebep olan birçok çevre kirletici unsur bulunmakla birlikte karbondioksit $\left(\mathrm{CO}_{2}\right)$ emisyonu halen sera gazı salınımında başat unsur olmaya devam etmektedir (IEA, 2011: 205). Yavuz (2014) çalışmasında Türkiye'de temel sera gazının \%81.1 'lik pay ile $\mathrm{CO}_{2}$ olduğunu belirtmiştir. Bu bağlamda Türk ekonomisi 2002-2010 yılları arasında yüksek büyüme hızları yakalamıştır. Aynı zamanda Türkiye'deki yıllık $\mathrm{CO}_{2}$ büyüme oranı 2000-2008 arasında \%4 olmuştur. $\mathrm{CO}_{2}$ büyüme hızı 1960'da \%0.5 iken 2008'de \%4'e yükselmiştir (Öztürk \& Acaravc1, 2013: 263). 
Bu çalışmanın amacı Türkiye'de 1990-2014 yılları arasında $\mathrm{CO}_{2}$ emisyonu, ham petrol talebi ve ekonomik büyüme arasındaki uzun dönemli ilişkiyi Pesaran vd. (2001) tarafından geliştirilen ARDL sınır testi yardımıyla analiz etmektir. Çalışmanın ikinci bölümünde $\mathrm{CO}_{2}$ emisyonu, ham petrol talebi ve ekonomik büyüme ilişkisi hakkında yapılmış çalışmalar değerlendirilecektir. Üçüncü bölümde, veri seti ve kullanılacak yöntem hakkında bilgi verilecek. Dördüncü bölümde, ampirik uygulama sonuçlarına yer verilmektedir. Sonuç kısmında ise araştırmada elde edilen sonuçlara yönelik değerlendirme ve politika önerileri yer almaktadır.

\section{Literatür Taraması}

$\mathrm{CO}_{2}$ emisyon modellemeleri genellikle dört ana kategoriye ayrılmaktadır (Du vd.; 2012: 372);

- Ulusal seviyedeki zaman serisi verilerine dayanan ve tipik olarak GSMH, enerji gibi verilere dayanan analizler.

- İkinci yöntem, temelden tepeye kadar yapılan sektör odaklı analizlerdir. Bu yöntemde bir yılın verisi baz yılı olarak alınmakta ve oluşturulan senaryoya göre yapılan tahminlerle gelecek trendler tespit edilmeye çalışılmaktadır.

- Üçüncü yöntem sistem optimizasyonudur. ABD Enerji Bakanlığı ve Uluslararası Enerji Ajansı (IEA) bu yöntemle her yıl raporlar yayınlamaktadır.

- Son yöntem ise girdi-çıktı analizi ile hesaplanabilir genel denge modelleridir.

Tablo: 1

Seçilmiş Literatür Özeti

\begin{tabular}{|c|c|c|c|c|}
\hline Yazar(lar) & $\begin{array}{l}\text { Zaman } \\
\text { Aralığı }\end{array}$ & Ülke & Yöntem & Sonuç \\
\hline $\begin{array}{l}\text { Kraft ve Kraft } \\
\text { (1978) }\end{array}$ & $\begin{array}{l}1947- \\
1974\end{array}$ & $\mathrm{ABD}$ & Granger Nedensellik & $\mathrm{GDP} \rightarrow \mathrm{EC}$ \\
\hline Stern (1993) & $\begin{array}{l}1947- \\
1990\end{array}$ & $\mathrm{ABD}$ & Çokdeğişkenli VAR & $\mathrm{EC} \rightarrow \mathrm{GDP}$ \\
\hline Soytaş vd. (2001) & $\begin{array}{l}1960- \\
1995\end{array}$ & Türkiye & Eşbütünleşme & $\begin{array}{l}\text { EC ve GDP arasında eş } \\
\text { bütünleşik ilişki ve } \\
\mathrm{EC} \rightarrow \mathrm{GDP}\end{array}$ \\
\hline $\begin{array}{l}\text { Altınay ve } \\
\text { Karagöl (2005) }\end{array}$ & $\begin{array}{l}1950- \\
2000\end{array}$ & Türkiye & Granger Nedensellik & $\mathrm{EC} \rightarrow \mathrm{GDP}$ \\
\hline $\begin{array}{l}\text { Lee ve Chang } \\
(2005)\end{array}$ & $\begin{array}{l}1954- \\
2003\end{array}$ & Tayvan & $\begin{array}{l}\text { Johansen Eşbütünleşme } \\
\text { ve Granger Nedensellik }\end{array}$ & $\begin{array}{l}\text { EC ve GDP arasında eş } \\
\text { bütünleşik ilişki ve } \\
\mathrm{EC} \rightarrow \mathrm{GDP}\end{array}$ \\
\hline $\begin{array}{l}\text { Jobert ve Karanfil } \\
(2007)\end{array}$ & $\begin{array}{l}1960- \\
2003\end{array}$ & Türkiye & $\begin{array}{l}\text { Johansen Eşbütünleşme } \\
\text { ve Granger Nedensellik }\end{array}$ & $\begin{array}{l}\text { EC ve GDP arasında eş } \\
\text { bütünleşik ilişki yok ve EC - } \\
\text {---- GDP }\end{array}$ \\
\hline Ho ve Siu (2007) & $\begin{array}{l}1966- \\
2002\end{array}$ & Hong Kong & $\begin{array}{l}\text { Eşbütünleşme ve VEC } \\
\text { Modeli }\end{array}$ & $\begin{array}{l}\text { EC ve GDP arasında eş } \\
\text { bütünleşik ilişki ve } \\
\mathrm{EC} \rightarrow \mathrm{GDP}\end{array}$ \\
\hline $\begin{array}{l}\text { Lise ve Van } \\
\text { Montford (2007) }\end{array}$ & $\begin{array}{l}1970- \\
2003\end{array}$ & Türkiye & Eşbütünleşme & $\begin{array}{l}\text { EC ve GDP arasında eş } \\
\text { bütünleşik ilişki ve } \\
\text { GDP } \rightarrow \text { EC }\end{array}$ \\
\hline Karanfil (2008) & $\begin{array}{l}1970- \\
2005\end{array}$ & Türkiye & $\begin{array}{l}\text { Granger Nedensellik ve } \\
\text { Eşbütünleşme }\end{array}$ & $\begin{array}{l}\text { EC ve GDP arasında eş } \\
\text { bütünleşik ilişki ve } \\
\mathrm{GDP} \rightarrow \mathrm{EC}\end{array}$ \\
\hline Ang (2008) & $\begin{array}{l}1971- \\
1999\end{array}$ & Malezya & Johansen Eşbütünleşme & $\begin{array}{l}\text { EC ve GDP arasında eş } \\
\text { bütünleşik ilişki ve } \\
\text { GDP } \rightarrow \text { EC }\end{array}$ \\
\hline Erdal vd. (2008) & $\begin{array}{l}1970- \\
2006\end{array}$ & Türkiye & Johansen Eşbütünleşme & $\begin{array}{l}\text { EC ve GDP arasında eş } \\
\text { bütünleşik ilişki ve EC } \leftrightarrow \\
\text { GDP }\end{array}$ \\
\hline
\end{tabular}


Alper, F.Ö. \& A.E. Alper (2017), “Karbondioksit Emisyonu, Ekonomik Büyüme, Enerji Tüketimi İlişkisi: Türkiye İçin Bir ARDL Sınır Testi Yaklaşımı”, Sosyoekonomi, Vol. 25(33), 145-156.

\begin{tabular}{|c|c|c|c|c|}
\hline Tang (2008) & $\begin{array}{l}1972- \\
2003\end{array}$ & Malezya & ARDL Eşbütünleşme & $\begin{array}{l}\text { EC ve GDP arasında eş } \\
\text { bütünleşik ilişki yok ve EC } \\
\leftrightarrow \text { GDP }\end{array}$ \\
\hline $\begin{array}{l}\text { Bowden ve Payne } \\
(2009)\end{array}$ & $\begin{array}{l}1949- \\
2006\end{array}$ & $\mathrm{ABD}$ & $\begin{array}{l}\text { Toda-Yamamoto } \\
\text { Nedensellik }\end{array}$ & $\mathrm{EC} \rightarrow \mathrm{GDP}$ \\
\hline Halıcıŏlu (2009) & $\begin{array}{l}1960- \\
2005\end{array}$ & Türkiye & ARDL Eşbütünleşme & $\begin{array}{l}\text { EC ve GDP arasında eş } \\
\text { bütünleşik ilişki ve GDP ---- } \\
\text { EC }\end{array}$ \\
\hline Payne (2009) & $\begin{array}{l}1949- \\
2006\end{array}$ & $\mathrm{ABD}$ & $\begin{array}{l}\text { Toda-Yamamoto } \\
\text { Nedensellik }\end{array}$ & GDP ---- EC \\
\hline $\begin{array}{l}\text { Soytaş ve Sar1 } \\
(2009)\end{array}$ & $\begin{array}{l}1960- \\
2000\end{array}$ & Türkiye & $\begin{array}{l}\text { Toda-Yamamoto } \\
\text { Nedensellik }\end{array}$ & GDP ---- EC \\
\hline Odhiambo (2009) & $\begin{array}{l}1971- \\
2006\end{array}$ & Tanzanya & ARDL Eşbütünleşme & $\begin{array}{l}\text { EC ve GDP arasında eş } \\
\text { bütünleşik ilişki }\end{array}$ \\
\hline Tiwari (2011) & $\begin{array}{l}1971- \\
2005\end{array}$ & Hindistan & $\begin{array}{l}\text { Johansen Eşbütünleşme } \\
\text { ve Granger Nedensellik }\end{array}$ & $\begin{array}{l}\text { EC ve GDP arasında eş } \\
\text { bütünleşik ilişki } \mathrm{CO} 2 \rightarrow \mathrm{GDP}\end{array}$ \\
\hline Saboori (2012) & $\begin{array}{l}1980- \\
2009\end{array}$ & Malezya & ARDL Eşbütünleşme & $\begin{array}{l}\mathrm{GDP} \text { ve } \mathrm{CO}_{2} \text { arasında eş } \\
\text { bütünleşik ilişki }\end{array}$ \\
\hline $\begin{array}{l}\text { Farhani ve Rejeb } \\
\text { (2012) }\end{array}$ & $\begin{array}{l}1973- \\
2008\end{array}$ & $\begin{array}{l}\text { Cezayir, Kıbrıs, Misır, İran, İsrail, Ürdün, Kuveyt, Fas, } \\
\text { Umman, S. Arabistan, Sudan, Suriye, Tunus, Türkiye, } \\
\text { BAE }\end{array}$ & Panel Eşbütünleşme & $\begin{array}{l}\mathrm{GDP}, \mathrm{CO}_{2} \text { ve } \mathrm{EC} \text { arasında eş } \\
\text { bütünleşik ilişki }\end{array}$ \\
\hline $\begin{array}{l}\text { Öztürk ve } \\
\text { Acaravc1 (2013) }\end{array}$ & $\begin{array}{l}1960- \\
2007 \\
\end{array}$ & Türkiye & ARDL Eşbütünleşme & $\begin{array}{l}\mathrm{GDP}, \mathrm{CO}_{2} \text { ve } \mathrm{EC} \text { arasında eş } \\
\text { bütünleşik ilişki }\end{array}$ \\
\hline Yavuz (2014) & $\begin{array}{l}1960- \\
2007\end{array}$ & Türkiye & $\begin{array}{l}\text { Johansen ve Gregory- } \\
\text { Hansen Eşbütünleşme }\end{array}$ & $\begin{array}{l}\mathrm{GDP}, \mathrm{CO}_{2} \text { ve } \mathrm{EC} \text { arasında eş } \\
\text { bütünleşik ilişki }\end{array}$ \\
\hline $\begin{array}{l}\text { Kasman ve } \\
\text { Duman (2015) }\end{array}$ & $\begin{array}{l}1992- \\
2010\end{array}$ & $\begin{array}{l}\text { Bulgaristan, Hırvatistan, Çek Cumhuriyeti, Estonya, } \\
\text { Macaristan, İrlanda, Litvanya, Letonya, Makedonya, } \\
\text { Malta, Polonya, Romanya, Slovakya, Slovenya, Türkiye }\end{array}$ & Panel Eşbütünleşme & $\begin{array}{l}\mathrm{GDP}, \mathrm{CO}_{2} \text {, Ticaret, } \\
\text { şehirleşme ve EC arasında } \\
\text { eş bütünleşik ilişki. }\end{array}$ \\
\hline $\begin{array}{l}\text { Twerefou, Poku } \\
\text { ve Bekoe (2016) }\end{array}$ & $\begin{array}{l}1970- \\
2010\end{array}$ & Gana & ARDL Eşbütünleşme & EKC hipotezi geçerli değil. \\
\hline $\begin{array}{l}\text { Doğan ve } \\
\text { Türkekül (2016) }\end{array}$ & $\begin{array}{l}1960- \\
2010\end{array}$ & $\mathrm{ABD}$ & ARDL Eşbütünleşme & EKC hipotezi geçerli değil. \\
\hline
\end{tabular}

Not: $E C \rightarrow G D P:$ Nedensellik yönü enerji talebinden ekonomik büyümeye doğru.

$G D P \rightarrow E C:$ Nedensellik yönü ekonomik büyümeden enerji talebine doğru.

GDP ---- EC: Nedensellik yok.

\section{Model, Yönetm ve Veri Seti}

$\mathrm{CO}_{2}$ emisyonu, ekonomik büyüme ve enerji tüketimi arasındaki ilişkinin araştırıldığı çalışmamızda (1) numaralı denklemde ifade edilen model kullanılmıştır;

$$
\mathrm{LNCO}_{2_{t}}=\alpha_{0}+\alpha_{1} \mathrm{LNGDP}_{t}+\alpha_{2} \operatorname{LNOIL}_{t}+\varepsilon_{t}
$$

Değişkenler ile açıklayııı bilgiler Tablo 2'de belirtilmiştir:

Tablo: 2

Değişkenler Hakkında Açıklayıcı Bilgiler

\begin{tabular}{|c|c|c|c|c|c|}
\hline Değişken İsmi & Birim & Ortalama & Standart Sapma & Minimum & Maximum \\
\hline LNCO $_{2}$ & Kiloton & 5.32 & 0.10 & 5.16 & 5.50 \\
\hline LNGDP & USD & 11.59 & 0.11 & 11.43 & 11.78 \\
\hline LNOIL & Bin ton & 4.38 & 0.05 & 4.21 & 4.44 \\
\hline
\end{tabular}

$\mathrm{CO}_{2}$ emisyonu, ekonomik büyüme ve enerji tüketimi arasındaki ilişki incelenirken Pesaran vd. (2001) tarafından geliştirilen ARDL (Autoregressive Distributed Lag) yöntemi kullanılcaktır. ARDL sınır testi yaklaşımının çeşitli avantajları bulunmaktadır. Bu avantajlardan ilki, ARDL yöntemi serilerin I(0) veya I(1) olmasına bakılmaksızın uygulanabilir. Daha da önemlisi dinamik sınırsız bir hata düzeltme modeli (UECM) elde edilebilmektedir. UECM kısa dönem dinamiklerle, uzun dönem eşitlikleri, herhangi bir uzun dönem bilgi kaybı olmadan entegre edebilmektedir (Shahbaz \& Lean; 2012: 475). Modelin ARDL formu (2) numaralı denklemde belirtilmiştir: 


$$
\begin{aligned}
& C O_{2_{t}}=f\left(G D P_{t}, O I L_{t}\right) \\
& \begin{array}{l}
\Delta \ln C O_{2_{t}}=b_{0}+\sum_{i=1}^{m} b_{1 i} \Delta \ln C O_{2_{t-i}}+\sum_{i=0}^{n} b_{2 i} \Delta \ln G D P_{t-i}+\sum_{i=0}^{p} b_{3 i} \Delta \ln O I L_{t-i}+ \\
b_{4} \ln C O_{2_{t-1}}+b_{5} \ln G D P_{t-1}+b_{6} \operatorname{lnOIL}_{t-1}+\varepsilon_{t}
\end{array}
\end{aligned}
$$

$\Delta$ terimi birinci fark operatörünü, $b_{0}$ eğilim (drift) katsayısı, $b_{1}, b_{2}$ ve $b_{3}$ katsayıları kısa dönem dinamik ilişkiyi ve $b_{4}, b_{5}$ ve $b_{6}$ katsayıları ise uzun dönem dinamik ilişkiyi ifade etmektedir. Analizde optimal gecikme uzunluğu Akaike bilgi kriteri (AIC) yardımıyla belirlenmektedir.

$$
\begin{aligned}
& H_{0}=b_{4}=b_{5}=b_{6}=0 \\
& H_{1}=b_{4} \neq b_{5} \neq b_{6} \neq 0
\end{aligned}
$$

ARDL yönteminde iki asimptotik kritik sınır kullanılmaktadır. Eğer elde edilen F istatistik değeri kritik üst sınırı geçerse, boş hipotez reddedilir, yani değişkenler arasında uzun dönemli bir ilişki olduğu kabul edilir. Eğer $\mathrm{F}$ istatistik değeri kritik alt sınırın altında kalırsa boş hipotez reddedilemez ve değişkenler arasında uzun dönemli ilişki olmadığ sonucuna varılır. Eğer F istatistik değeri iki kritik sınır arasında kalırsa, herhangi bir yorum yapılamaz.

Boş hipotez reddedilir ve değişkenler arasında uzun dönemli bir ilişki olduğu tespit edilirse, (3) numaralı denklemde belirtilen UECM tahmin edilir:

$$
\begin{aligned}
& \Delta \operatorname{lnCO}_{2_{t}}=c_{0}+\sum_{i=1}^{m} c_{1 i} \Delta \operatorname{lnCO} O_{2_{t-i}}+\sum_{\mathrm{I}=0}^{n} c_{2 i} \Delta \ln G D P_{t-i}+\sum_{i=0}^{p} c_{3 i} \Delta \ln O I L_{t-i}+ \\
& \delta E C M_{t-i}+\mu_{t}
\end{aligned}
$$

(3) numaralı denklemde $\Delta$ terimi, birinci fark operatörünü; $E C M_{t-i}$ terimi, hata düzeltme terimi ve $\delta$ terimi ise değişkenlerin bir şok karşısında ne kadar hızlı dengeye yöneleceklerini gösteren hata düzeltme terimi katsayısıdır.

Analizde 1985-2014 aralığını kapsayan, yıllık veriler kullanılmıştır. $\mathrm{CO}_{2}$ ve GDP değişkenleri verileri Dünya Bankası veri tabanından; yurt içi ham petrol tüketimi verisi (OIL) ise Eurostat veri tabanından elde edilmiştir. Ampirik literatüre bağlı kalınarak bütün değişkenler analize doğal logaritmaları alınarak dâhil edilmiştir.

\section{Ampirik Sonuçlar}

Öztürk ve Acaravcı (2013)'e göre ARDL yaklaşımında eğer değişkenlerden birinin birim kök derecesi I(1)'den büyükse, Pesaran vd. (2001) ve Narayan (2005) tarafindan bulunan kritik değerler kullanılamaz. Bu kritik değerler I(0) ve I(1) temelli oluşturulmuştur. $\mathrm{Bu}$ nedenle analizin ilk aşamasında değişkenlere birim kök testi yaparak ARDL sınır testi yaklaşımının varsayımlarına uyup uymadı̆̆ına bakılması gerekmektedir.

$\mathrm{Bu}$ amaçla çalışmada serilerin durağanlığının incelenmesi için Genişletilmiş Dickey ve Fuller (ADF) Testi ve Phillips ve Perron (PP) testleri kullanılmıştır. ADF ve PP 
testlerinin, boş hipotezlerinde serilerin birim köke sahip olduğu; alternatif hipotezlerinde ise serilerin durağan olduğu ifade edilmektedir. (3) numaralı tablo değişkenlere ait ADF ve PP test sonuçlarını vermektedir:

Tablo: 3

Birim Kök Test Sonuçları

\begin{tabular}{|c|c|c|c|c|}
\hline \multirow{2}{*}{ Düzey } & \multicolumn{3}{|c|}{$\mathrm{ADF}$} & PP \\
\hline & Sabitli & Sabitli-Trendli & Sabitli & Sabitli-Trendli \\
\hline $\mathrm{LNCO}_{2}$ & $-0.004(0)$ & $-2.54(0)$ & $0.422(5)$ & $-2.549(0)$ \\
\hline LNGDP & $0.061(0)$ & $-2.52(0)$ & $0.161(2)$ & $-2.520(0)$ \\
\hline LNOIL & $-1.750(0)$ & $-2.16(0)$ & $-1.750(0)$ & $-2.092(2)$ \\
\hline \multirow{2}{*}{ Birinci Farkları } & \multicolumn{2}{|r|}{$\mathrm{ADF}$} & \multicolumn{2}{|r|}{ PP } \\
\hline & Sabitli & Sabitli-Trendli & Sabitli & Sabitli-Trendli \\
\hline $\mathrm{LNCO}_{2}$ & $-4.96(0)^{*}$ & $-4.85(0)^{*}$ & $-5.195(4)^{*}$ & $-5.070(4)^{*}$ \\
\hline LNGDP & $-4.66(0)^{*}$ & $-4.55(0)^{*}$ & $-4.666(1)^{*}$ & $-4.554(1)^{*}$ \\
\hline LNOIL & $-4.83(0)^{*}$ & $-4.17(1)^{*}$ & $-4.931(3)^{*}$ & $-8.144(11)^{*}$ \\
\hline
\end{tabular}

Not: ADF testinde parantez içindeki değerler Schwarz Bilgi kriteri kullanılarak seçilen gecikme uzunluklarını ifade etmektedir ve maksimum gecikme uzunluğu 4 olarak alınmıştır. PP testinde optimal gecikme uzunluğu belirlemek için Bartlett kernel yöntemi ve Newey-West Bandwith kriterlerinden yararlanılmıştır. *\%5 düzeyinde anlamlılı̆̆ ifade etmektedir.

(3) numaralı tabloda da belirtildiği üzere seriler için ADF ve PP birim kök testleri uygulandığında tüm serilerin birim köke sahip olduğu veya durağan olmadığı sonucuna varılmıştır. Serilerin birinci farkı alınarak yeniden birim kök testi uygulandığında serilerin durağanlaştığı sonucuna ulaşılmıştır. Dolayısıyla ADF ve PP birim kök testleri sonucunda tüm serilerin bütünleşme derecesinin I(1) olduğu belirlenmiștir. Bu sonuçlar Pesaran vd. (2001) ve Narayan (2005) tarafından önerilen sınır testi yaklaşımının kullanılmasına izin vermektedir. Tablo 4'de ARDL sınır testi sonuçları verilmiştir. Buna göre $\mathrm{CO}_{2}$, ekonomik büyüme ve ham petrol tüketimi arasında uzun dönemli bir ilişkinin varlığı kanıtlanmıştır.

Tablo: 4

ARDL Sınır Testi Sonuçları

\begin{tabular}{|c|c|c|}
\hline Tahmin Edilen Eşitlik & \multicolumn{2}{|c|}{$\mathrm{LCO}_{2}=\mathrm{f}(\mathrm{LGDP}, \mathrm{LOIL})$} \\
\hline F İstatistiği & \multicolumn{2}{|c|}{9.51} \\
\hline Optimum Gecikme Uzunluğu & \multicolumn{2}{|c|}{$[4,2,4]$} \\
\hline Asimptotik Kritik Değerler & Alt Sinır, I(0) & Üst Sınır, I(1) \\
\hline$\% 1$ & 5.15 & 6.26 \\
\hline$\% 5$ & 3.53 & 4.42 \\
\hline$\% 10$ & 2.91 & 3.69 \\
\hline Diagnostik Testler & \\
\hline & \multirow{2}{*}{\multicolumn{2}{|c|}{0.928}} \\
\hline Düzeltilmiş $R^{2}$ & & 0.914 \\
\hline F İstatistiği & \multicolumn{2}{|c|}{$344.468(0.000)$} \\
\hline Breusch-Godfrey Testi & \multicolumn{2}{|c|}{$1.580(0.3398)$} \\
\hline ARCH LM Testi & \multicolumn{2}{|c|}{$0.109(0.745)$} \\
\hline Jarque-Bera Normallik Testi & \multicolumn{2}{|c|}{$1.356(0.507)$} \\
\hline Ramsey Reset Testi & \multicolumn{2}{|c|}{$2.043(0.226)$} \\
\hline
\end{tabular}

Not: Gecikme uzunluğunun belirlenmesinde AIC kullanılmıştır. Kritik değer sınırları Narayan (2005: 1987, Case II) 'den alınmıştır. Parantez içerisindeki rakamlar olasılık değerlerini göstermektedir.

Tablo 4'de sunulan diagnostik test sonuçları ARDL modelinde otokorelasyon, değişen varyans ve fonksiyonel form sorunlarının olmadığını ayrıca hataların normal dağılım sergilediğini ortaya koymaktadır. 
Tablo: 5

ARDL (4, 2, 4) Tahmin Sonuçları

\begin{tabular}{|c|c|c|}
\hline \multirow{2}{*}{ Değişkenler } & \multicolumn{2}{|c|}{ Bağımlı Değişken: LCO2 } \\
\cline { 2 - 3 } & Katsay1 & $5.108(0.0037)$ \\
\hline LNCO $_{2}(-1)$ & 0.787 & $-4.394(0.0071)$ \\
\hline $\operatorname{LNCO}_{2}(-2)$ & -0.796 & $2.504(0.0542)$ \\
\hline $\mathrm{LNCO}_{2}(-3)$ & 0.227 & $-3.662(0.0146)$ \\
\hline $\mathrm{LNCO}_{2}(-4)$ & -0.290 & $12.800(0.0001)$ \\
\hline LNGDP & 1.128 & $-6.030(0.0018)$ \\
\hline LNGDP(-1) & -1.094 & $4.678(0.0054)$ \\
\hline LNGDP(-2) & 0.824 & $-3.198(0.0240)$ \\
\hline LNOIL & 0.189 & $2.939(0.0323)$ \\
\hline LNOIL(-1) & 0.147 & $-3.449(0.0183)$ \\
\hline LNOIL(-2) & 0.194 & $0.438(0.6790)$ \\
\hline LNOIL(-3) & 0.045 & $2.679(0.0438)$ \\
\hline LNOIL(-4) & 0.313 & $-4.344(0.0074)$ \\
\hline C & -4.795 & \\
\hline
\end{tabular}

Tablo 6'da $\mathrm{LNCO}_{2}$ değişkenin bağımlı değişken olduğu modelde, uzun dönem katsayılar gösterilmektedir.

Tablo: 6

Uzun Dönem Katsayılar

\begin{tabular}{|c|c|c|}
\hline \multirow{2}{*}{ Değişkenler } & \multicolumn{2}{|c|}{$\begin{array}{c}\text { Bağımlı Değişken: } \\
\text { LNCO }_{2}\end{array}$} \\
\cline { 2 - 3 } & Katsay1 & t istatistiği (p değeri) \\
\hline LNGDP & 0.800 & $24.478(0.000)$ \\
\hline LNOIL & 0.114 & $3.638(0.0240)$ \\
\hline C & -4.472 & $-10.271(0.000)$ \\
\hline
\end{tabular}

Aynı zamanda Türk ekonomisinde incelenen dönemde yaşanan yapısal değişimlerden dolayı bir veya daha çok yapısal kırılma olabileceğinden Brown vd. (1975) çalışmasında önerilen kısa ve uzun dönem katsayıların uygunluğunu test etmek amacıyla cumulative sum (CUSUM) ve cumulative sum of squares (CUSUMSQ) testleri yapılmıştır.

CUSUM ve CUSUMSQ testleri, Chow testinde olduğu gibi kırılma noktalarının belirlenmesine gerek duymamaktadır. Dolayısıyla kırılma tarihlerinin önceden belirlenmesine gerek yoktur. (1) numaralı şekil CUSUM ve CUSUMSQ test istatistiklerinin $\% 5$ anlamlılık düzeyinde kritik sınırların içerisinde kaldığını göstermektedir. Bunun anlamı tahmin edilen parametrelerin incelenen dönem içerisinde istikrarlı olduğudur. 


\section{Şekil: 1 \\ CUSUM ve CUSUMSQ Testleri}
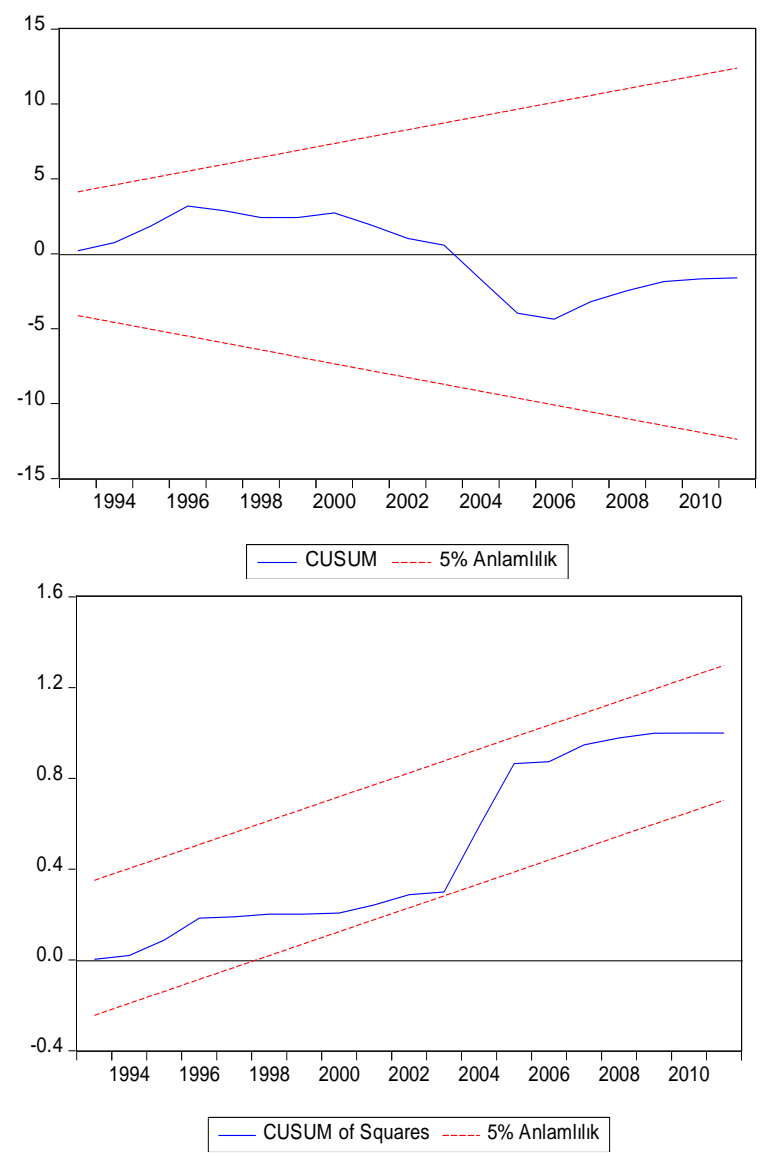

Tablo 7'de Hata Düzeltme Modeli sonuçları gözükmektedir. Kısa dönem uyarlanma sürecini anlayabilmek için Hata düzeltme katsayısının (ECM-1) işaretine ve büyüklüğüne bakılmaktadır. ECM(-1) katsayısı 0 ile -1 arasında ise, uyarlanma süreci uzun dönem denge değerine tek düze bir şekilde olur. ECM(-1) katsayısı pozitif veya -2'den küçükse dengeden uzaklaşıldığını, -1 ile -2 arasındaysa uzun dönem denge değerinin etrafında azalan dalgalanmalar sergilediğini ifade etmektedir. Analizde ECM(-1) katsayısı negatif ve istatistiki olarak anlamlı bulunmuştur. Bu durum değişkenler arasındaki uzun dönemli ilişkinin varlığını bir başka açıdan kanıtlamaktadır. Hata düzeltme katsayısı -1 ile -2 arasında olduğu için, hata düzeltme sürecinde uzun dönem denge değerlerin etrafinda azalan dalgalanmalar göstererek dengeye ulaşılmaktadır (Alam \& Quazi; 2003: 97). 
Alper, F.Ö. \& A.E. Alper (2017), “Karbondioksit Emisyonu, Ekonomik Büyüme, Enerji Tüketimi İlişkisi: Türkiye İçin Bir ARDL Sınır Testi Yaklaşımı”, Sosyoekonomi, Vol. 25(33), 145-156.

Tablo: 7

Hata Düzeltme Modeli

\begin{tabular}{|c|c|c|}
\hline \multirow{2}{*}{ Değişkenler } & \multicolumn{2}{|c|}{ Bağımlı Değişken: $\Delta$ LNCO2 } \\
\cline { 2 - 3 } & Katsay1 & t istatistiği (p değeri) \\
\hline$\Delta$ LNGDP & 1.120 & $12.800(0.000)$ \\
\hline$\Delta$ LNOIL & 0.190 & $3.198(0.0250)$ \\
\hline C & -4.795 & $-4.344(0.0074)$ \\
\hline ECM(-1) & -1.072 & $-5.118(0.0037)$ \\
\hline
\end{tabular}

\section{Sonuç ve Öneriler}

$\mathrm{Bu}$ çalışmada ekonomik büyüme ve enerji tüketiminin karbondioksit salınımı üzerindeki etkisi, zaman serisi analizinde önemli bir yeri olan eşbütünleşme metodolojisi çerçevesinde incelenmiştir. Bu amaçla Türkiye ekonomisine ilişkin 1985-2014 dönemini kapsayan yıllık verilerden oluşan 30 gözlemlik bir veri seti oluşturulmuştur. Serilerin birim kök test sonuçları birinci farkında durağanlığa işaret etmektedir. Böylece ARDL metodu olarak bilinen sınır testi yaklaşımı kullanılarak söz konusu model tahmin edilmiştir. Hesaplanan F istatistik değeri üst kritik sınır değerinden büyük olduğu için, analize dahil edilen değişkenler arasında uzun dönem denge ilişkisinin varlığı tespit edilmiştir.

ARDL modelinin tahmin sonuçları ekonomik büyüme ve ham petrol tüketimi değişkenlerinin karbondioksit salınımı ile pozitif yönde ilişki içerisinde olduğunu ve sırasıyla 0.80 ve 0.114 değerlerini aldığını ortaya koymaktadır. Diğer bir ifadeyle, ele alınan dönemde ekonomik büyüme ve enerji tüketimi Türkiye ekonomisinde çevre kirliliğini arttıran önemli belirleyicilerdir.

Diğer taraftan, hata düzeltme modeli bulguları değişkenler arasında istikrarlı uzun dönem ilişkinin varlığını doğrular niteliktedir. Hata düzeltme katsayısının (-1.072) negatif ve istatistiki olarak anlamlı bulunması bunun en önemli kanıtıdır. Çalışmanın bulguları Öztürk ve Acaravcı (2013), Altıntaş (2013), Saatçi ve Dumrul (2011) ve Yavuz (2014) sonuçları ile örtüşmektedir.

Çalışmadan elde edilen bulguların önemli politik sonuçları vardır. İlk olarak önümüzdeki on yılda ekonomik büyüme devam ettikçe toplam karbondioksit emisyonu artmaya devam edeceği için, Türkiye'nin ekonomik büyüme önceliği olduğu sürece, aktif çevre kirliliği azaltıcı önlemleri devreye sokması şarttır. İkinci önemli sonuç ise bu politikaların uygulanabilmesi için Türkiye'de devlet tarafından kurumlara destek verilmelidir.

Bu destek sadece finansal anlamda değil, aynı zamanda kömür ve petrol tüketiminin yenilenebilir enerji kaynaklarıyla değişimini cesaretlendirici; tüketicileri temiz enerji, ısınma ve ulaşım taleplerini arttırıcı politikalarda olmalıdır.

Giderek büyüyen bir sorun haline gelen iklim değişikliğinin önlenmesi için politika yapıcıların mutlak anlamda ekonomik büyümeden ziyade yeşil büyümeye (green growth) odaklanması gereklidir. Yeşil büyüme, ekonomik büyümeyi de pozitif anlamda etkileyecektir. Çünkü yeşil büyüme yaşam kalitesini, sosyal refahı arttıracak ve sürdürülebilir büyümeye olanak tanıyacak, çevresel kalitedeki sürekli artışlarla beraber, 
Alper, F.Ö. \& A.E. Alper (2017), “Karbondioksit Emisyonu, Ekonomik Büyüme, Enerji Tüketimi İlişkisi: Türkiye İçin Bir ARDL Sınır Testi Yaklaşımı”, Sosyoekonomi, Vol. 25(33), 145-156.

beşeri sermayenin genel sağlık düzeyini arttırmak suretiyle uzun dönemde verimliliği arttıracaktır.

\section{Kaynaklar}

Alam, I. \& R. Quazi (2003), "Determinants of capital flight: An econometric case study of Bangladesh", International Review of Applied Economics, 17(1), 85-103.

Altıntaş, H. (2013), “Türkiye'de Birincil Enerji Tüketimi, Karbondioksit Emisyonu ve Ekonomik Büyüme İlişkisi: Eşbütünleşme ve Nedensellik Analizi”, Eskişehir Osmangazi Üniversitesi İktisadi ve İdari Bilimler Dergisi, 8(1), 263-294.

Altinay, G. \& E. Karagol (2005), "Electricity consumption and economic growth: evidence from Turkey", Energy Economics, 27(6), 849-856.

Ang, J.B. (2008), "Economic development, pollutant emissions and energy consumption in Malaysia", Journal of Policy Modeling, 30(2), 271-278.

Bowden, N. \& J.E. Payne (2009), "The causal relationship between US energy consumption and real output: a disaggregated analysis", Journal of Policy Modeling, 31(2), 180-188.

Brown, R.L. \& J. Durbin \& J.M. Evans (1975), "Techniques for testing the constancy of regression relationships over time", Journal of the Royal Statistical Society, Series B (Methodological), 149-192.

Brundtland, G. \& M. Khalid \& S. Agnelli \& S. Al-Athel \& B. Chidzero \& L. Fadika \& M. Singh (1987), Our Common Future, <http://www.un-documents.net/our-common-future.pdf>, 19.08.2016.

Dogan, E. \& B. Turkekul (2016), “ $\mathrm{CO}_{2}$ emissions, real output, energy consumption, trade, urbanization and financial development: testing the EKC hypothesis for the USA", Environmental Science and Pollution Research, 23(2), 1203-1213.

Du, L. \& C. Wei \& S. Cai (2012), "Economic development and carbon dioxide emissions in China: Provincial panel data analysis", China Economic Review, 23(2), 371-384.

Erdal, G. \& H. Erdal \& K. Esengün (2008), "The causality between energy consumption and economic growth in Turkey", Energy Policy, 36(10), 3838-3842.

Farhani, S. \& J. Ben Rejeb (2012), "Energy consumption, economic growth and $\mathrm{CO}_{2}$ emissions: Evidence from panel data for MENA region", International Journal of Energy Economics and Policy (IJEEP), 2(2), 71-81.

Halicioglu, F. (2009), "An econometric study of $\mathrm{CO}_{2}$ emissions, energy consumption, income and foreign trade in Turkey”, Energy Policy, 37(3), 1156-1164.

Ho, C.Y. \& K.W. Siu (2007), “A dynamic equilibrium of electricity consumption and GDP in Hong Kong: an empirical investigation”, Energy Policy, 35(4), 2507-2513.

IEA (2011), International Energy Agency World Energy Outlook 2011, <https://www.iea.org/publications/freepublications/publication/WEO2011_WEB.pdf>, 06.08.2016.

Intergovernmental Panel on Climate Change (IPCC), (2007), Climate Change Synthesis Report 2007, <https://www.ipcc.ch/pdf/assessment-report/ar4/wg3/ar4_wg3_full_report.pdf>, 29.08.2016.

Jobert, T. \& F. Karanfil (2007), "Sectoral energy consumption by source and economic growth in Turkey”, Energy Policy, 35(11), 5447-5456. 
Alper, F.Ö. \& A.E. Alper (2017), “Karbondioksit Emisyonu, Ekonomik Büyüme, Enerji Tüketimi İlişkisi: Türkiye İçin Bir ARDL Sınır Testi Yaklaşımı", Sosyoekonomi, Vol. 25(33), 145-156.

Karanfil, F. (2008), "Energy consumption and economic growth revisited: Does the size of unrecorded economy matter?", Energy Policy, 36(8), 3029-3035.

Kasman, A. \& Y.S. Duman (2015), " $\mathrm{CO}_{2}$ emissions, economic growth, energy consumption, trade and urbanization in new EU member and candidate countries: a panel data analysis", Economic Modelling, 44, 97-103.

Kraft, J. \& A. Kraft (1978), "Relationship between energy and GNP”, Journal of Energy, Finance and Development, 3:2(2), 401-403.

Lee, C.C. \& C.P. Chang (2005), "Structural breaks, energy consumption, and economic growth revisited: evidence from Taiwan", Energy Economics, 27(6), 857-872.

Lise, W. \& K. Van Montfort (2007), "Energy consumption and GDP in Turkey: Is there a cointegration relationship?", Energy Economics, 29(6), 1166-1178.

Narayan, P.K. (2005), "The saving and investment nexus for China: evidence from cointegration tests", Applied Economics, 37(17), 1979-1990.

Odhiambo, N.M. (2009), "Energy consumption and economic growth nexus in Tanzania: An ARDL bounds testing approach", Energy Policy, 37(2), 617-622.

Ozcan, B. (2013), "The nexus between carbon emissions, energy consumption and economic growth in Middle East countries: A panel data analysis", Energy Policy, 62, 1138-1147.

Ozturk, I. \& A. Acaravci (2013), "The long-run and causal analysis of energy, growth, openness and financial development on carbon emissions in Turkey", Energy Economics, 36, 262-267.

Payne, J.E. (2009), "On the dynamics of energy consumption and output in the US", Applied Energy, 86(4), 575-577.

Pesaran, M.H. \& Y. Shin \& R.J. Smith (2001), "Bounds testing approaches to the analysis of level relationships", Journal of Applied Econometrics, 16(3), 289-326.

Saboori, B. \& J. Sulaiman \& S. Mohd (2012), "Economic growth and $\mathrm{CO}_{2}$ emissions in Malaysia: a cointegration analysis of the environmental Kuznets curve", Energy Policy, 51, 184-191.

Saatçi, M. \& Y. Dumrul (2011), "Çevre Kirliliği ve Ekonomik Büyüme İlişkisi: Çevresel Kuznets Eğrisinin Türk Ekonomisi İçin Yapısal Kırılmalı Eş-Bütünleşme Yöntemiyle Tahmini”, Erciyes Üniversitesi İktisadi ve İdari Bilimler Fakültesi Dergisi, (37), 65-86.

Shahbaz, M. \& H.H. Lean (2012), "Does financial development increase energy consumption? The role of industrialization and urbanization in Tunisia", Energy Policy, 40, 473-479.

Soytas, U. \& R. Sari (2009), "Energy consumption, economic growth, and carbon emissions: challenges faced by an EU candidate member", Ecological Economics, 68(6), 16671675.

Stern, D.I. (1993), "Energy and economic growth in the USA: a multivariate approach", Energy Economics, 15(2), 137-150.

Stern, N.H. \& S. Peters \& V. Bakhshi \& A. Bowen \& C. Cameron \& S. Catovsky \& S.L. Garbett (2006), Stern Review: The economics of climate change, (Vol. 30), Cambridge: Cambridge University Press.

Soytas, U. \& R. Sari \& O. Ozdemir (2001), "Energy consumption and GDP relation in Turkey: a cointegration and vector error correction analysis", Economies and Business in Transition: Facilitating Competitiveness and Change in the Global Environment Proceedings, 838-844.

Tiwari, A.K. (2011), "Energy consumption, $\mathrm{CO}_{2}$ emissions and economic growth: Evidence from India”, Journal of International Business and Economy, 12(1), 85-122. 
Tang, C.F. (2008), “A re-examination of the relationship between electricity consumption and economic growth in Malaysia", Energy Policy, 36(8), 3077-3085.

Twerefou, D.K. \& F. Adusah-Poku \& W. Bekoe (2016), “An empirical examination of the Environmental Kuznets Curve hypothesis for carbon dioxide emissions in Ghana: an ARDL approach", Environmental \& Socio-economic Studies, 4(4), 1-12.

Yavuz, N.Ç. (2014), " $\mathrm{CO}_{2}$ emission, energy consumption, and economic growth for Turkey: Evidence from a cointegration test with a structural break", Energy Sources, Part B: Economics, Planning, and Policy, 9(3), 229-235. 